\title{
TECNOLOGIAS GOOGLE E APRENDIZAGEM COLABORATIVA EM UM CURSO À DISTÂNCIA: UM RELATO DE EXPERIÊNCIA
}

JOÃO PESSOA/PB MAIO/2018

\author{
ESTÊVÃO DOMINGOS SOARES DE OLIVEIRA - UEaD UFPB - estevaodso@gmail.com \\ HERCÍLIO DE MEDEIROS SOUSA - UEaD UFPB - contato@herciliomedeiros.com.br \\ JEFFERSON CARDOSO OLIVEIRA - UEaD UFPB - jefferson.iesp@gmail.com
}

Tipo: Relato de Experiência Inovadora (EI)

Categoria: Métodos e Tecnologias

Setor Educacional: EDUCAÇÃO MÉDIA E TECNOLÓGICA, EDUCAÇÃO SUPERIOR, EDUCAÇÃO CONTINUADA EM GERAL

\begin{abstract}
RESUMO
Este artigo apresenta um relato de experiência do uso do Google Docs para a aprendizagem colaborativa no contexto da Educação a Distância. Este relato foi resultado do curso online Tecnologias Google para Educação, que teve como objetivo apresentar como as ferramentas Google podem contribuir para criar cenários de aprendizagem inovadores. O curso foi realizado em 2017 e teve como Ambiente Virtual de Aprendizagem a plataforma Moodle. O público participante se constituiu de professores de instituições de ensino, públicas e privadas, bem como licenciandos, resultando num total de 25 pessoas. Para a identificação das contribuições da ferramenta, foi analisada uma atividade desenvolvida durante o curso. Denominada de Leitura Colaborativa, ela teve como proposta a leitura e posterior discussão pelos participantes, com a orientação do professor/tutor, acerca de um determinado texto. Como resultado, concluiu-se que a ferramenta tem potencial para ser uma grande aliada no processo de ensino-aprendizagem pautado na aprendizagem colaborativa. Assim, o Google Docs possui meios que tornam a aprendizagem mais significativa, e ao mesmo tempo favorece a interação e compartilhamento de saberes entre alunos e professor.
\end{abstract}

Palavras-chave: Educação a Distância, Aprendizagem colaborativa, Google Docs 


\section{Introdução}

Nos debates acerca da educação é sempre comum a discussão sobre qual ou quais metodologias de ensino são mais apropriadas para o desencadear do processo de ensino-aprendizagem, de acordo com o contexto social. Há algum tempo, estudiosos da educação vem discutindo a necessidade de práticas educacionais que quebrem as barreiras da reprodução do conhecimento, infelizmente ainda presentes em boa parte do cotidiano escolar brasileiro. A proposta da educação deve ir além da simples memorização e repetição de determinado conteúdo, estendendo-se, assim, ao contato, discussão, reflexão, aplicação e função social que cada conhecimento deve propiciar. Ou seja, que, inicialmente, a informação se torne conhecimento, e, em seguida, que esse conhecimento tenha um significado social relevante para o estudante, contribuindo para a sua prática cidadã e luta pela igualdade social. Sobre isso Paulo Freire afirma que:

Não devemos chamar o povo à escola para receber instruções, postulados, receitas, ameaças, repreensões e punições, mas para participar coletivamente da construção de um saber, que vai além do saber de pura experiência feito, que leve em conta as suas necessidades e o torne instrumento de luta, possibilitando-Ihe transformar-se em sujeito de sua própria história. (1991, p. 16)

No entanto, devido a diversos fatores, desde burocráticos até os didáticos, o processo de ensino-aprendizagem, por vezes, não consegue sequer alcançar a primeira proposta da educação, que é transformar a informação em conhecimento para os alunos. $O$ tradicionalismo metodológico e didático impregnado ao longo da história da educação brasileira ainda está fortemente presente em nosso cenário educacional, e para que esse paradigma seja superado é preciso o estudo e aplicação de novos métodos educativos.

Diante disso, voltando para o debate sobre metodologias de ensino que dispõem de uma contribuição maior e mais adequada para o processo educacional, encontra-se a Aprendizagem Colaborativa, que, segundo Torres e Irala (2007), recusa vigorosamente a prática que leva à reprodução do conhecimento e a exclusão do aluno. Com isso, ela é caracterizada pelo reconhecimento de sua potencialidade em promover a aprendizagem onde o aluno é colocado como agente principal na construção do conhecimento, através de estímulos que levam a interação, negociação e resolução de problemas. Sobre isso os autores afirmam que na aprendizagem colaborativa:

\footnotetext{
(...) espera-se que ocorra a aprendizagem como efeito colateral de uma interação entre pares que trabalham em sistema de interdependência na resolução de problemas ou na realização de uma tarefa proposta pelo professor. Segundo alguns estudiosos desse tipo de aprendizagem, a interação em grupos realça a aprendizagem, mais do que em um esforço individual. Uma aprendizagem mais eficiente, assim como um trabalho mais eficiente, é colaborativa e social em vez de competitiva e isolada. A troca de ideias com outras pessoas melhora 0 pensamento e aprofunda o entendimento (TORRES e IRALA, ano, p. 70).
} 
A aprendizagem colaborativa possui algumas características próprias. Segundo Matthews apud Torres e Irala (2007, p. 72-73), algumas delas são apresentadas no Quadro 1:

Quadro 1. Características da Aprendizagem Colaborativa

\begin{tabular}{|c|c|}
\hline Características & Descrição \\
\hline Aprender ativamente & $\begin{array}{l}\text { Aqui o aluno sai daquela velha postura passiva tão presente } \\
\text { no ensino tradicional e passa a desenvolver autonomia e } \\
\text { responsabilidade por sua própria aprendizagem. Podendo } \\
\text { sugerir métodos e informações relevantes ao decorrer das } \\
\text { aulas. }\end{array}$ \\
\hline Professor como facilitador & $\begin{array}{l}\text { O professor deixa de ser fonte única de conhecimento e } \\
\text { assume postura de facilitador da aprendizagem. É quem } \\
\text { auxilia na mediação entre conteúdo e aluno, esclarecendo } \\
\text { dúvidas, propiciando momentos e atividade (problemas) que } \\
\text { levem o aluno a refletir e de forma autônoma construa seu } \\
\text { próprio conhecimento. }\end{array}$ \\
\hline $\begin{array}{l}\text { Professor e aluno ensinam e } \\
\text { aprendem de forma compartilhada }\end{array}$ & $\begin{array}{l}\text { Tanto o aluno como o professor adquirem novos } \\
\text { aprendizados numa relação de troca entre eles de } \\
\text { experiências, ideias e opiniões. Pois, é frequente casos } \\
\text { onde alunos conseguem a resolução de problemas } \\
\text { diferentemente da forma proposta pelo professor, que } \\
\text { muitas vezes auxilia na aprendizagem de outros alunos. }\end{array}$ \\
\hline $\begin{array}{l}\text { Equilíbrio entre atividades em grupo } \\
\text { e aula expositiva. }\end{array}$ & $\begin{array}{l}\text { o professor não apenas expõe o conteúdo nem realiza } \\
\text { atividades individuais dirigidas com frequência. Mas procura } \\
\text { balancear com atividades realizadas em grupo, de modo } \\
\text { que a proposta final seja alcançada através do debate e } \\
\text { consenso entre alunos. }\end{array}$ \\
\hline $\begin{array}{l}\text { Desenvolver habilidades sociais e } \\
\text { de trabalho em equipe. }\end{array}$ & $\begin{array}{l}\text { Por meio das atividades realizadas em grupo, o aluno ao ter } \\
\text { que agir e interagir harmonicamente para a resolução do } \\
\text { problema tem de entrar em consenso com os demais } \\
\text { alunos, desenvolvendo habilidades sociais e de trabalho em } \\
\text { equipe. Compartilhando saberes próprios e competências já } \\
\text { adquiridas. É importante para o desenvolvimento social do } \\
\text { discente a lida com pessoas que pensam diferente, } \\
\text { principalmente quando se trata de alcançar um objetivo } \\
\text { comum ao meio. }\end{array}$ \\
\hline
\end{tabular}


Fonte: Matthews apud Torres e Irala (2007).

Os autores reconhecem que a participação em atividades de grupo propicia o aumento das habilidades do aluno no uso de seu próprio conhecimento. E, neste sentido, o aluno torna-se mais responsável pelo seu aprendizado e desenvolvimento intelectual, além de favorecer na habilidade de reflexão sobre seus próprios processos mentais e suas próprias crenças. E, com isso, este aluno melhora as habilidades sociais e de trabalho em equipe por meio da concordância, o que favorece, também, o reconhecimento do valor da diversidade, como elemento fundamental em prol de uma democracia multicultural (Matthews apud Torres e Irala (2007).

A Comunidade de Práticas trata da aprendizagem colaborativa, afirmando que "a colaboração acontece quando os participantes se sentem provocados a expressarem seu entendimento do significado que está sendo construído no processo de interação". Diante disso, afirma-se mais uma vez sobre a necessidade de superação da relação vertical entre professor-aluno, em vista de quebrar as barreiras e resistências que ainda existem tão fortemente nesta relação. Reconhecendo que por meio da interação o professor pode extrair novos conhecimentos dos alunos ao serem provocados a expor suas experiências.

Ainda sobre as vantagens propiciadas por essa metodologia, recentemente, em abril do corrente ano, a plataforma de aprendizagem adaptativa Geekie publicou uma notícia onde discute sobre a temática e lista dois principais benefícios de sua adesão. Primeiro, que sua prática por meio de ambientes virtuais possibilita que os alunos possam, de forma investigativa, buscar informações em plataformas, sites e demais espaços online, para a complementação e auxílio no estudo proposto pelo professor, bem como o enriquecimento do diálogo entre alunos e professor. Com isso, quebrando o paradigma do professor como sendo a única fonte de saber no processo educativo.

Segundo, que propicia atividades em grupo de modo a trabalhar mutuamente diferentes habilidades dos alunos. Tendo por finalidade superar as dificuldades de aprendizagem individuais através da construção coletiva do saber, onde uns compartilham com os outros as competências já dominadas para se alcançar a aprendizagem significativa, e não apenas memorativa. Essa colaboração, em especial entre alunos, possibilita além da construção do conhecimento o sentimento de satisfação pessoal em ajudar o outro. Ultrapassando as relações de construção do conhecimento para a dimensão humana em suas relações interpessoais.

Portanto, a sala de aula, tanto virtual como presencial, precisa ser um espaço em que os 
discentes tenham a oportunidade de aprender e produzir autonomamente seus conhecimentos por meio da resolução de problemas com a colaboração de todos os envolvidos. E nesse processo o aluno é impulsionado a desenvolver a capacidade de exercer inteiramente a sua cidadania. Além de exercitar o respeito mútuo às opiniões diversas. Como argumenta Torres e Irala (2007):

Em um contexto escolar, a aprendizagem colaborativa seria duas ou mais pessoas trabalhando em grupos com objetivos compartilhados, auxiliando-se mutuamente na construção de conhecimento. Ao professor não basta apenas colocar, de forma desordenada, os alunos em grupo, deve sim criar situações de aprendizagem em que possam ocorrer trocas significativas entre os alunos e entre estes e o professor. (ano, p.71)

Buscando identificar e discutir a relevância dessa metodologia de ensino, este artigo tem como finalidade apresentar um relato de experiência do uso da ferramenta Google Docs para a aprendizagem colaborativa. O Google Docs é um serviço para web, bem como para android e iOS, que possibilita a criação, edição e visualização de documentos de texto, e permite o compartilhamento entre usuários. A experiência foi realizada durante o curso online Tecnologias Google para Educação, que teve como objetivo apresentar como as ferramentas Google podem contribuir para criar cenários de aprendizagem inovadores.

\section{Metodologia}

Como dito anteriormente, a atividade escolhida foi denominada de Leitura Colaborativa. Esta atividade refere-se a uma experiência realizada durante o curso online Tecnologias Google para Educação, que teve como objetivo apresentar como as ferramentas Google podem contribuir para criar cenários de aprendizagem inovadores. $O$ curso foi realizado em 2015, através do Ambiente Virtual de Aprendizagem Moodle. Seu público se constituiu por professores de instituições de ensino, públicas e privadas, bem como licenciandos, resultando num total de 25 pessoas. A atividade teve como proposta a leitura e construção de um diálogo entre os participantes acerca de um determinado texto sugerido pelo professor, utilizando a ferramenta Google Docs.

Após a escolha da atividade a ser analisada, foram feitos recortes de fragmentos das interações realizadas pelos alunos no Google Docs para que, em seguida, fosse realizada a análise e discussão, buscando identificar as contribuições que a ferramenta traz para a metodologia de ensino aprendizagem colaborativa. A escolha do fragmento se deu por ele apresentar elementos que caracterizam a colaboração mútua, através do diálogo construído por três alunos sob o destaque e comentário inicial de um outro aluno.

Por fim, após as análises, realizou-se o levantamento dos resultados a fim de responder 
o objetivo geral do artigo, que é saber como o Google Docs contribui para o desencadear do processo de ensino e aprendizagem, pautado na aprendizagem colaborativa.

\section{Resultados e Discussão}

Conforme proposto inicialmente, na tentativa de identificar as contribuições que o Google Docs propicia para a aprendizagem colaborativa, destacou-se alguns recortes da atividade proposta durante o curso online. A partir destes recortes pôde-se discutir onde e em que momento aparecem as características dessa metodologia de ensino.

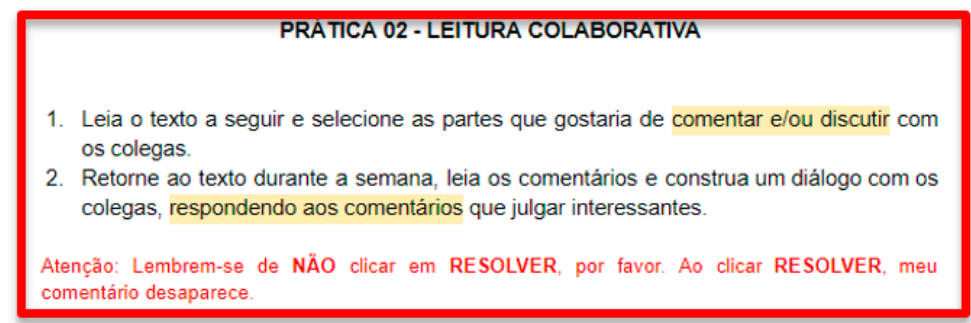

Colaboração e Cooperação

A aprendizagem colaborativa tem sido foco das diversas instituições de ensino superior que começam a dinamizar suas atividades em parte ou na sua totalidade em ambientes virtuais de aprendizagem (AVA). Para Moraes (2005, p. 200), nos AVA a aprendizagem, embora seja individual, é também influenciada pelos processos de natureza coletiva, pautados nas conversações entre individuos que compartilham o mesmo espaço virtual. Nessa nova

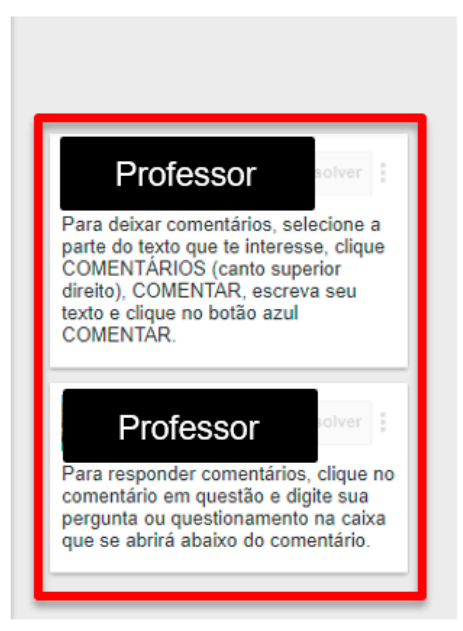

Figura 01 - Orientações para os alunos participantes. Fonte: Autores (2018).

A proposta da atividade em questão consistia em o aluno selecionar no texto as partes interessantes e que gostariam de comentar e/ou discutir com os colegas, e, em seguida, ler os comentários e construir uma discussão com os mesmos, respondendo aos comentários. O professor orienta, dentro da própria ferramenta, como os alunos devem usá-la para que assim possam inserir os comentários e dar início a realização da atividade, como mostra a Figura 01. 


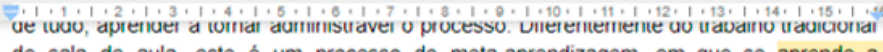
de sala de aula, este é um processo de meta-aprendizagem, em que se aprende a aprender, o que implica saber formular problemas e gerenciá-los, năo bastando apenas resolvê-los. É também necessário preparar estruturas de informaçăo, e năo apenas usar a estrutura que um livro texto oferece; fazer evoluir e intercambiar o que se aprende, em vez de apenas aplicar o que já se sabe; usar análise exploratória heuristica, e năo apenas os algoritmos fornecidos pelo curriculo; construir modelos de teste, e não apenas absorve-los dos outros; considerar o desempenho a partir dos resultados do grupo e não apenas de seus próprios; criar mapas de açăo e não apenas seguir instruç̋̃es.

Como promover a aprendizagem colaborativa ou a interaprendizagem deve ser um dos focos das docentes ao desenvolverem o curso, procurando promover situaçбes de aprendizagem que provoquem esse tipo de interação, e que a construção do conhecimento se dê, em grande parte, na troca dos pares.

Hoje, a partir das possibilidades do digital, emergem softwares que buscam proporcionar práticas colaborativas na rede, porém não é a disponibilidade desses programas que garantirá a ocorrência das trocas colaborativas, mas sim o entendimento do valor da produção coletiva pelos aprendizes. Colocar nas instituições educacionais os recursos tecnológicos colaborativos é uma das formas de contribuir para a formação do ser social transformador, possibilitando e estimulando 0 desenvolvimento das caracteristicas colaborativas do homem que, por muito tempo, ficou relegada em favor da corrida individualista, que há várias décadas vem sendo repassada como a única maneira de convivência na chamada sociedade capitalista.

Entre esses recursos tecnológicos, o wiki é um dos que mais tem sido usado. É uma interface que possibilita a criacão de textos em colaboracão com os componentes de um

Aluno A

Segundo a UNESCO "Essa perspectiva deve no futuro inspirar orientar as reformas educacionais, seia na elaboracão dos proaramas ou Mostrar mais

\section{Aluno B}

O PPP da escola onde trabalho, tem sempre os 4 pilares da educação como orientação, e encerra com:"A Educação deve estruturar-se em torno destes quatro aprendizados considerados fundamentais, que, ao longo da vida de cada pessoa, se lornarăo os pilares de seus

\section{Aluno C}

Aprender a aprender" A frase está bem realcionada ao principio que as vezes eu uso que é seguinte: quando vai esquecer em pouco tempo e quando você irá atrás para entender

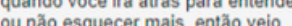

Figura 02 - Comentários dos alunos na atividade. Fonte: Autores (2018).

$\mathrm{Na}$ Figura 02, pode-se identificar uma das contribuições possibilitada pela aprendizagem colaborativa em espaços de construção coletiva do saber. A contribuição consiste na possibilidade que os alunos têm de apresentar informações relevantes ao aprendizado, retiradas de plataformas, sites, livros ou textos extras, para a complementação e auxílio no estudo proposto pelo professor, bem como o enriquecimento do diálogo entre alunos e professor. Com isso, quebrando o paradigma do professor como sendo a única fonte de saber no processo educativo. Isso se dá quando o Aluno A apresenta a perspectiva da UNESCO sobre o trecho por ele destacado no texto.

Partindo do comentário do Aluno A outros dois alunos (Aluno B e Aluno C) construíram um diálogo apresentando suas concepções acerca do que foi destacado pelo colega de curso. O Aluno B, por exemplo, fez a relação do "aprende a aprender" com sua experiência de trabalho, que no caso se trata de uma escola. Permitindo aos companheiros de curso a reflexão de suas próprias vivências com o tema debatido. Essa colaboração e troca de saberes entre alunos também é uma das principais características dessa metodologia. Segundo Matthews apud Torres e Irala (2007) "ensinar e aprender são experiências compartilhadas entre professores e alunos" e requer mais que esforço individual (p. 73). 
Nessa perspectiva, podemos nos remeter a Freire que vê o aprender do aluno como criação e liberdade, sendo fundamental que a prática pedagógica promova a sua autonomia. Isso só acontece quando o professor respeita os saberes dos aprendizes, e propõe uma relação dialógica, onde "quem ensina aprende ao ensinar e quem aprende ensina ao aprender" (FREIRE, 2001, p. 25). Assim, passa a valorizar as produções dos alunos, estimulando-os no sentido de aumentar a confiança no seu potencial criador.

Através da participação e da colaboração, o usuário contribui com a inteligência coletiva (LÉVY, 1996), agregando elementos e pontos de vista variados em determinada temática. Assim, estamos exercitando a passagem do modelo um-todos comum nas enciclopédias para o modelo todos-todos, formando co-autores nesse processo coletivo. Além de ressaltar sua importância no desenvolvimento de competências que geram a inclusão, pois à medida que os processos de inteligência coletiva se desenvolvem, "melhor a apropriação, por individuos e por grupos, das alterações técnicas, e menores são os efeitos de exclusão ou de destruição humana resultantes da aceleração do movimento tecnosocial" (LEVY, 1999, p. 29)

Inspirados no pensamento de Silva (2001), consideramos que é preciso se apropriar das possibilidades tecnológicas que nos permitem "ingressar dentro de uma obra" - a hibridação traz a idéia de fusão, de intervenção na mensagem do outro, de co-criação, de modificação. Deve-se derrubar as fronteiras entre autor/leitor/emissor/receptor, na medida em que é através da interatividade $e$ da intervenção que as mensagens vão se formando, se modificando a cada novo contato com o outro. O conhecimento de cada um, produto individual $e$ internalizado de vivências, leituras e reflexões, se enriquece e se modifica a cada possibilidade de troca com o outro e com os muitos registros do conhecimento

\section{Aluno D}

Uma das referências biográficas pode ser "PEDAGOGIA DA AUTONOMIA" (FREIRE, 2001, p.25).

Pedagogia da Autonomia é a última obra de Paulo Freire, publicada em vida Ele analisa a prática pedagógica vida.Ele analisa a pratica pedagogica de ser e de saber do educando.

\section{Aluno $\mathrm{E}$}

Isso mesmo Maria Cristina. Consultei o livro. Abraços

Rúbia

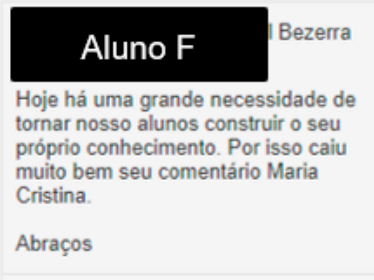

Figura 03 - Comentários dos alunos na atividade. Fonte: Autores (2018).

Em outras partes da atividade, como apresenta a Figura 03, há também outros diálogos entres os aprendentes. Tornando-a mais participativa e provocante, na medida em que ocorre convergência e divergência de pensamentos e de aprendizado. O concordar ou discordar dentro na perspectiva da colaboração é de suma importância, pois, exercita o respeito mútuo às opiniões diversas.

A ferramenta Google Docs é prática e de fácil manuseio, cabe ao professor instruir sobre sua usabilidade e saber propor aulas e atividades que estimulem e levem à interação, negociação e resolução de problemas. Ela possui uma variedade de instrumentos que auxiliam na aprendizagem colaborativa de forma lúdica. Como a possibilidade de debate pelo bate-papo, compartilhar links, anexar imagens, a escrita coletiva, dentre outros. Enquanto os alunos interagem e constroem conhecimento, o professor, além de interagir, pode acompanhar em tempo real ou não o desempenho através do feedback (que a própria ferramenta disponibiliza) do que foi modificado e realizado por cada aluno. O que auxilia na avaliação contínua sobre o desempenho deles, como dificuldades de compreensão e interação com os colegas, por exemplo.

Uma característica importante da aprendizagem colaborativa está ausente na atividade analisada, que é a mediação e interação do professor com os alunos. Percebe-se que em toda a atividade, e não só no fragmento, que o docente apenas propôs a atividade e instruiu quanto a sua realização. Essa falta de diálogo durante e após a atividade é uma das principais barreiras a ser enfrentada, tanto em momentos online quanto em momentos presenciais. É de extrema importância que o professor possa acompanhar e 
intervir sempre que preciso.

Com o uso das tecnologias para a educação, há modificações quanto o papel de professores e alunos. Trata-se de uma nova forma de aprendizagem, que, segundo Pozo (2007):

(...) mudar as formas de aprender dos alunos requer também mudar as formas de ensinar de seus professores. Por isso, a nova cultura da aprendizagem exige um novo perfil de aluno e de professor, exige novas funções discentes e docentes, as quais só se tornarão possíveis se houver uma mudança de mentalidade, uma mudança nas concepções profundamente arraigadas de uns e de outros sobre a aprendizagem e o ensino para encarar essa nova cultura da aprendizagem (POZO, 2007, p. 36).

O docente deve estar atento para não transferir para ambientes virtuais as mesmas práticas que 0 ensino em salas presenciais. Ele deve auxiliar na mediação entre conteúdo e aluno, esclarecendo dúvidas, estimulando a interação e o diálogo entre aprendentes, a troca de aprendizado e habilidades. Um dos grandes desafios do professore é nortear os alunos quanto à veracidade das informações existentes na rede e fazer com que as informações relevantes se tornem de fato conhecimento para os alunos. Para que isso ocorra, Pozo $(2007$, p. 36) elenca cinco capacidades para a gestão metacognitiva do conhecimento que devem ser desenvolvidas pelo discente, são elas: a) Competências para a aquisição de informação; b) Competências para a interpretação da informação; c) Competências para a análise da informação; d) Competências para a compreensão da informação; e) Competências para a comunicação da informação.

\section{Conclusões}

A partir das análises e dos resultados apresentados anteriormente, concluímos que a ferramenta Google Docs pode ser uma grande aliada no processo de ensino e aprendizagem pautado na metodologia da aprendizagem colaborativa. $O$ Docs possui meios que tornam a aprendizagem mais significativa, e ao mesmo tempo favorece a interação e compartilhamento de saberes entre alunos e professor.

E nesse sentido, o professor visto como mediador estimula os alunos à trocar experiências e à desenvolver seu lado investigativo. Portanto, ao analisar-se a Atividade Colaborativa observou-se a efetiva participação dos alunos e de fato apresenta características da colaboração.

Por outro lado, um aspecto bastante importante e que merece destaque, foi perceber o papel fundamental do professor da construção do saber. Como discutido anteriormente, é de extrema relevância a presença e acompanhamento contínuo dos alunos pelo 
professor. E, de acordo com a atividade analisada percebeu-se sua ausência, o que demonstra que tanto em espaços online quanto em espaços físicos ainda é difícil a superação de algumas práticas que dificultam o diálogo entre professores e alunos.

Se sabe que o uso do Google Docs para a educação ainda é um hábito não frequente, principalmente quando se trata da educação básica. Sua usabilidade se dá com mais constância no ensino superior, embora em tímida escala. Deve-se haver mais o incentivo ao uso dessa e outras ferramentas online, tento em vista sua contribuição para a construção coletiva do saber. Onde o aluno participa ativamente do processo de ensino e aprendizagem.

\section{Referências}

FREIRE, Paulo. A Educação na Cidade. São Paulo: Cortez; 1991.

Geekie. LORENZONI, Marcela. Aprendizagem colaborativa para alunos protagonistas. Disponível em: $<$ http://info.geekie.com.br/aprendizagem-colaborativa-protagonistas/>. Acesso em: 13 de Junho de 2016.

POZO, Juan Ignacio. A sociedade da aprendizagem e o desafio de converter informação em conhecimento. Fonte: REVISTA PÁTIO - Ano 8 - Agosto/Outubro 2004. Disponível em: $<$ http://www.udemo.org.br/A\%20sociedade.pdf $>$. Acesso em: 15 de Julho de 2016.

SlideShare, Comunidade de Práticas. Apresentação aprendizagem colaborativa. Disponível

em:

$<$ http://pt.slideshare.net/comunidadedepraticas/apresentacao-aprendizagem-

colaborativa-53081235>. Acesso em: 13 de agosto de 2016.

TORRES, Patrícia Lupion, org. Algumas vias para entretecer o pensar e o agir / Patrícia Lupion Torres [org.]. - Curitiba : SENAR-PR, 2007. 196p. (Aprendizagem colaborativa). 